\title{
Estudio Morfológico, Morfométrico e Histoquímico de los Epitelios de Revestimiento y Glandular de la Lengua de la Rana Toro, Rana catesbeiana
}

\author{
Morphological, Morphometrical and Histochemical Study of the Lining and Glandular Epithelia of \\ the Tongue of the Bullfrog Rana catesbeiana
}

Michel Farchi Guiraldelli; Ruberval A. Lopes; Miguel A. Sala \& Túlio Roberto V. P. Lopes

GUIRALDELLI, M.F.; LOPES, R.A.; SALA, M.A. \& LOPES, T.R.V.P. Estudio morfológico, morfométrico e histoquímico de los epitelios de revestimiento y glandular de la lengua de la rana toro, Rana catesbeiana. Int. J. Morphol., 29(1):226-233, 2011.

RESUMEN: La superficie dorsal de la lengua de la rana toro, Rana catesbeiana, presenta un epitelio simple cilíndrico, constituido por células caliciformes y raras células ciliadas. El dorso de la lengua posee numerosas papilas filiformes y algunas fungiformes. Las primeras poseen un epitelio simple cilíndrico, con células secretoras, mientras que las segundas poseen en la región apical, un disco sensorial con epitelio estratificado cilíndrico, con células basales, periféricas, glandulares y receptoras. A lo largo del dorso de la lengua existen numerosas glándulas tubulares, que penetran en profundidad, entremezclándose con las fibras musculares. El epitelio glandular es simple cilíndrico, con células secretoras y de sostén. Las primeras son las únicas en la base de la glándula y las segundas solo se encuentran en número escaso en el tercio superior. La superficie ventral de la lengua posee un epitelio estratificado, con células caliciformes y, entre éstas, células ciliadas. La morfometría de las glándulas mostró que son más cortas en la región anterior de la lengua (330 $\mu$ m) que en la región posterior $(450 \mu \mathrm{m})$. Las células secretoras de las glándulas linguales anteriores son menores $\left(1457,7 \mu \mathrm{m}^{3}\right)$ que en las posteriores $\left(2645,9 \mu \mathrm{m}^{3}\right)$. Lo mismo ocurre con los núcleos celulares: $130,0 \mu \mathrm{m}^{3}$ en las glándulas anteriores y $202,3 \mu \mathrm{m}^{3}$ en las posteriores. Las células secretoras de las glándulas linguales sintetizan producto rico en proteínas y mucopolisacáridos neutros, pudiendo caracterizarse como seromucoso. Las células caliciformes de las superficies dorsal y ventral secretan proteínas y mucopolisacáridos neutros, clasificándose como del tipo G1, mientras que las células de sostén de las glándulas superficiales de las papilas fungiformes secretan moco rico en mucopolisacáridos neutros, sulfomucinas y sialomucinas.

PALABRAS CLAVE: Lengua; Glándulas linguales; Morfometría; Histoquímica; Rana Toro; Rana catesbeiana.

\section{INTRODUCCIÓN}

El tipo de alimentación es un factor determinante del éxito de la adaptación de los vertebrados a su hábitat. En los tetrápodos, la lengua ejerce un papel esencial para la subsistencia y en los anfibios adultos, excepto pocas especies, es un órgano cuya estructura refleja una adaptación a la mudanza del medio acuático para el terrestre, donde se necesita un esfuerzo mayor para la ingestión de alimentos. Durante la metamorfosis en los anfibios las branquias desaparecen y el aparato que originaba su musculatura se adapta para producir los músculos linguales del adulto.

Usualmente, los anfibios viven próximos del agua dulce y la superficie de la mucosa bucal es húmeda. Además, las especies terrestres raramente están expuestas a condiciones severas de estiaje y el epitelio lingual no es queratinizado (Graziadei \& Dehan, 1971; Zylberberg, 1977; Iwasaki et al., 1989). Por otra parte, no hay una separación nítida entre lengua y glándulas salivales (Tucker, 1958). El epitelio lingual de los anfibios posee células con secreción que ejerce papel semejante a la saliva, de modo que la lengua sirve tanto para obtener alimentos como para humedecerlos (Graziadei \& Dehan; Zylberberg, 1977; Iwasaki et al., 1989). En la superficie dorsal de la lengua de muchos anfibios existen abundantes papilas con corpúsculos gustativos (Düring \& Andres, 1976; Iwasaki \& Kobayashi, 1989). Así, a las funciones de ingestión de alimentos y de salivación se agrega la función gustativa. 
Debido a su estructura altamente especializada, numerosos trabajos se dedicaron al estudio de la mucosa lingual de los anfibios. El primero que describió la morfología de las glándulas linguales fue Wiedersheim (1879), en Caecilia gracilis. Francis (1961), en un estudio comparativo de seis especies, demostró diferencias en la distribución de las glándulas linguales y su producto de secreción.

Hammerman (1969) describió siete tipos de células epiteliales: caliciformes, bastones, furcadas, fusiformes, cilíndricas ciliadas, cilíndricas diagonales y cúbicas, en la mucosa lingual de Rana catesbeiana. Stensaas (1971) describió cuatro tipos de epitelio en la mucosa lingual del sapo Calytocephalella gayi: estratificado ciliado sin papilas, en la superficie ventral; simple cilíndrico, en la mayor parte de la superficie dorsal; estratificado no queratinizado, en el vértice de las papilas filiformes, y estratificado cilíndrico, en el disco sensorial de las papilas fungiformes.

Nalavade \& Varute (1971) evidenciaron la distribución heterogénea de mucinas neutras, sulfomucinas y sialomucinas en las papilas fungiformes y filiformes, epitelio ventral y glándulas en lenguas de dos especies de anfibios, identificando varios tipos celulares en las papilas y en el epitelio ventral. Basados en la histoquímica, estos autores clasificaron las glándulas linguales en serosas (la totalidad en la rana y las posteriores profundas en el sapo) y mucosas (las superficiales posteriores en el sapo). Albanese-Carmignani \& Zaccone (1974) verificaron que las glándulas de la región anterior de la lengua de Discoglossus pictus son mucoserosas, mientras que las de la región posterior son seromucosas. Albanese-Carmignani et al. (1975) en Hyla arbórea, Rana esculenta y Bufo vulgaris, comprobaron que el epitelio ventral de la lengua era estratificado, con numerosas células caliciformes entre las cuales se disponen abundantes células ciliadas. En la superficie dorsal se observan papilas filiformes y fungiformes, numerosas glándulas tubulares y, menos frecuentes, glándulas tubulares ramificadas superficiales. Según los autores, las glándulas linguales de $H$. arbórea son seromucosas y las de $R$. esculenta y $B$. vulgaris son mucoserosas.

Zylberberg (1976) demostró que los tubos glandulares en Bufo bufo, Discoglossus pictus y Rana esculenta son constituidos por células mucoserosas y seromucosas, mientras que en Hyla arborea son seromucosas y en Alytes obstetricans serosas. Según Zylberberg (1977), las glándulas de la lengua de los anfibios se limitan a la superficie dorsal y los productos de secreción son de composición heterogénea. La secreción de las células glandulares externas es rica en mucopolisacáridos con una acidez que varía entre especies.
Albanese-Carmignani \& Zaccone (1977) observaron, en Bufo viridis y Rana graeca, que la superficie ventral de la lengua era revestida por un epitelio estratificado con numerosas células caliciformes, entre las cuales existen células ciliadas. La superficie dorsal de la lengua esta recubierta por un epitelio con papilas filiformes y fungiformes, con glándulas mucoserosas, tubulares y túbulo-alveolares. Navas et al. (1981), en las papilas del epitelio dorsal de la lengua de Rana ridibunda, caracterizaron varios tipos celulares. Excepto las células caliciformes, los otros tipos celulares son ricos en mucopolisacáridos neutros, con presencia variable de sulfomucinas, sialomucinas y proteínas.

Lopes et al. (1997) describieron, en la superficie dorsal de la lengua de Hyla fuscovaria, papilas filiformes y fungiformes con glándulas mucoserosas, ricas en mucopolisacáridos neutros, sialomucinas y proteínas. Junqueira \& Araujo (1998) observaron en la lengua de Bufo ictericus, glándulas con células ciliadas entre las células mucosas, mientras que Yu et al. (1998) además de las células ciliadas, describieron cinco tipos de células secretoras en las glándulas linguales de Rana esculenta.

Wistuba et al. (1999) demostraron dos tipos de células caliciformes en el epitelio lingual de Ambystoma mexicanum: el tipo I, con gránulos laxos, irregulares, y el tipo II, con gránulos de secreción que se fusionan en una única masa homogénea.

En el dorso de la lengua de Eurycea longicauda guttolineata el epitelio posee células superficiales planas y caliciformes, y, en la región marginal, células ciliadas. Fueron descritos dos tipos de células caliciformes, tipo A, con predominio de secreción ácida, y tipo B, con secreción neutra. Las células secretora de las glándulas linguales son PAS y azul alcian positivas en la región apical, mientras que solo se muestran positivas al azul alcian en la región basal (Opolka et al., 2003).

El presente trabajo tiene por objetivo estudiar morfológicamente el epitelio de la mucosa lingual, analizando morfométrica e histoquímicamente las glándulas linguales de la rana toro Rana catesbeiana.

\section{MATERIAL Y MÉTODO}

Las lenguas de 6 ranas toro (Rana catesbeiana) fueron disecadas e inmediatamente fijadas en formol neutro al $10 \%$ y líquido de Bouin, durante 24 h. Después de incluidas, fueron cortadas con $6 \mu \mathrm{m}$ de espesor. Algunos cortes fueron teñidos con hematoxilina y eosina para análisis 
histológica e histométrica, mientras que cortes adyacentes fueron usados para estudio histoquímico. Fueron empleadas técnicas para demostración de las siguientes substancias:

Mucopolisacáridos neutros: Ácido peryódico-Schiff (PAS) (McManus, 1946); PAS después de digestión con alfaamilasa (Spicer et al., 1967); PAS después de digestión con tripsina; PAS después de digestión con cloroformo; PAS después de acetilación (McManus \& Cason, 1950).

Mucopolisacáridos ácidos: Azul alcian 8GX-300 (AB) a pH 1,0 (Lev \& Spicer, 1964); AB a pH 2,5 (Mowry, 1956); AB pH 2,5 después de metilación; $\mathrm{AB}$ pH 2,5 después de metilación y saponificación (Spicer \& Lillie, 1959); AB pH 2,5 después de hidrólisis ácida (Quintarelli et al., 1961); AB pH 2,5 después de digestión con hialuronidasa testicular (Quintarelli, 1963); AB pH 2,5 + PAS (Vialli, 1955).

Proteínas: Azul de bromofenol (Mazia et al., 1953).

La caracterización histoquímica de las células secretoras de las glándulas linguales de $R$. catesbeiana fue basada en los criterios de Gabe \& St. Girons (1969).

Los métodos morfométricos fueron empleados para estudiar las células secretoras y sus núcleos, estimándose los siguientes parámetros: diámetro medio, relación diámetro mayor/diámetro menor, perímetro, área, volumen, rela- ción volumen/área, factor de forma, índice de contorno y excentricidad (Sala et al., 1994).

La longitud de las glándulas fue medida sobre dibujos realizados con cámara clara, con aumento de 1000 x.

\section{RESULTADOS}

La mucosa de la superficie dorsal de la lengua de $R$. catesbeiana está revestida por un epitelio simple cilíndrico, constituido por escasas células ciliadas y células secretoras sin cilios (células glandulares o caliciformes). En toda la superficie dorsal de la lengua se observan papilas filiformes y fungiformes. Las papilas filiformes poseen un epitelio simple cilíndrico con células secretoras. Las papilas fungiformes poseen en la región apical un disco sensorial, constituido por epitelio estratificado cilíndrico, con células basales, periféricas, glandulares y receptoras, mientras que en la superficie lateral hay células secretoras. Del mismo modo, en toda la extensión del dorso de la lengua existen numerosas glándulas tubulares que penetran profundamente en la musculatura lingual, de forma que, muchas veces, las glándulas parecen estar envueltas por esas fibras (Fig. 1). Las paredes glandulares están constituidas por un epitelio simple cilíndrico, con células secretoras y de sostén. Las células secretoras se encuentran a lo largo de toda la pared glandular, mientras que las células de sostén existen, en número

Tabla I. Valores medios de los parámetros morfométricos de los núcleos y de las células secretoras de las glándulas linguales de Rana catesbeiana.

\begin{tabular}{lcccc}
\hline \multirow{2}{*}{ Parámetros } & \multicolumn{3}{c}{ Región de la lengua } \\
\cline { 2 - 4 } & \multicolumn{2}{c}{ Ápice } & \multicolumn{2}{c}{ Dorsal posterior } \\
\cline { 2 - 4 } & Núcleo & Célula & Núcleo & Célula \\
\hline Diámetro may or $(\mu \mathrm{m})$ & 7,0 & 18,4 & 8,4 & 21,4 \\
Diámetro menor $(\mu \mathrm{m})$ & 5,6 & 10,8 & 6,4 & 13,8 \\
Diámetro medio $(\mu \mathrm{m})$ & 6,3 & 14,1 & 7,3 & 17,2 \\
Relación D/d & 1,3 & 1,7 & 1,3 & 42,5 \\
Perímetro $(\mu \mathrm{m})$ & 14,9 & 35,6 & 17,7 & 233,7 \\
Área $\left(\mu \mathrm{m}^{2}\right)$ & 34,4 & 157,1 & 42,1 & 2645,9 \\
Volumen $\left(\mu \mathrm{m}^{3}\right)$ & 130,0 & 1457,7 & 202,3 & 11,3 \\
Relación V/A & 4,1 & 9,3 & 4,8 & 0,8 \\
Excentricidad & 0,6 & 0,8 & 0,6 & 1,1 \\
Coeficiente de forma & 1,8 & 1,6 & 2,6 & 2,8 \\
Índice de contorno & 2,7 & 2,8 & 2,7 & \\
\hline
\end{tabular}


escaso, solamente en el tercio superior de la pared glandular. El epitelio posee una membrana basal evidente, lámina propia escasa y musculatura muy desarrollada. Es posible observar algunos folículos linfáticos.

La mucosa de la superficie ventral de la lengua de $R$. catesbeiana posee un epitelio estratificado, con numerosas células caliciformes. Entre estas células, existen numerosas células epiteliales ciliadas (Fig. 2). En la mitad posterior de la lengua, el epitelio se hace más delgado, con células caliciformes más redondeadas y células ciliadas mas bajas. Próximo a la punta de la lengua, el epitelio muestra doblas suaves, semejantes a papilas, pero sin la estructura característica de estas.

Fue posible determinar morfométricamente, que las glándulas localizadas en la extremidad anterior de la lengua son menores, con cerca de $330 \mu \mathrm{m}$ de longitud, mientras que en la región dorsal posterior miden alrededor de 450 $\mu \mathrm{m}$ de longitud.

La Tabla II muestra los parámetros morfométricos de las células secretoras y sus núcleos, en las glándulas de la punta de la lengua y de la región dorsal posterior. Se puede observar que las células secretoras de las glándulas y sus núcleos son menores en la punta de la lengua que en la región dorsal posterior.

El producto de secreción de las células de las glándulas linguales aparece como gránulos citoplasmáticos PASpositivos (Figs. 1 y 2). La digestión previa con amilasa o cloroformo y metanol no alteró la intensidad de la reacción. La digestión previa con tripsina, al contrario, disminuyó la intensidad de la reacción del PAS, y después de acetilación la reacción desapareció completamente. Los gránulos citoplasmáticos no se tiñeron con azul alcian a pH 2,5 o 1,0. Los gránulos se tiñeron con fucsina cuando se usó la técnica del PAS + AB y mostraron reacción positiva con azul de bromofenol.

Las células caliciformes del epitelio del dorso y vientre de la lengua mostraron un producto de secreción en forma de gránulos PAS-positivos (Figs. 1 y 2), reacción que no se alteró después de la acción de la amilasa, tripsina o cloroformo y metanol. La acetilación, al contrario, bloqueó completamente la reacción al PAS.

Tabla II. Resultados de las reacciones histoquímicas para mucopolisacáridos y proteínas en las células secretoras de las glándulas linguales, células caliciformes del epitelio dorsal y ventral y células glandulares superficiales de sostén de las papilas fungiformes de la lengua de Rana catesbeiana.

\begin{tabular}{|c|c|c|c|}
\hline Reacción & Célula secretora & Célula calicifor me & Célula de sostén \\
\hline PAS & ++ & ++ & ++ \\
\hline PAS + acetilación & - & - & - \\
\hline PAS + amilasa & ++ & ++ & ++ \\
\hline $\mathrm{PAS}+$ cloroformo + metanol & ++ & ++ & ++ \\
\hline PAS + tripsina & + & + & ++ \\
\hline $\mathrm{AB} 2,5$ & - & - & ++ \\
\hline $\mathrm{AB} 1,0$ & - & - & + \\
\hline $\mathrm{AB} 2,5+$ metilación & - & - & - \\
\hline $\mathrm{AB} 2,5+$ metilación + saponificación & - & - & + \\
\hline $\mathrm{AB} 2,5$ + hidrólisis ácida & - & - & + \\
\hline $\mathrm{AB} 2,5+$ hialuronidas a testicular & - & - & + \\
\hline $\mathrm{PAS}+\mathrm{AB} 2,5$ & $\mathrm{R}$ & $\mathrm{R}$ & $\mathrm{V}$ \\
\hline Azul de bromofenol & + & + & - \\
\hline
\end{tabular}

(++) Reacción intensa; (+) reacción media; (+) reacción débil; (-) reacción negativa. (R) coloración roja; (V) coloración violeta. 


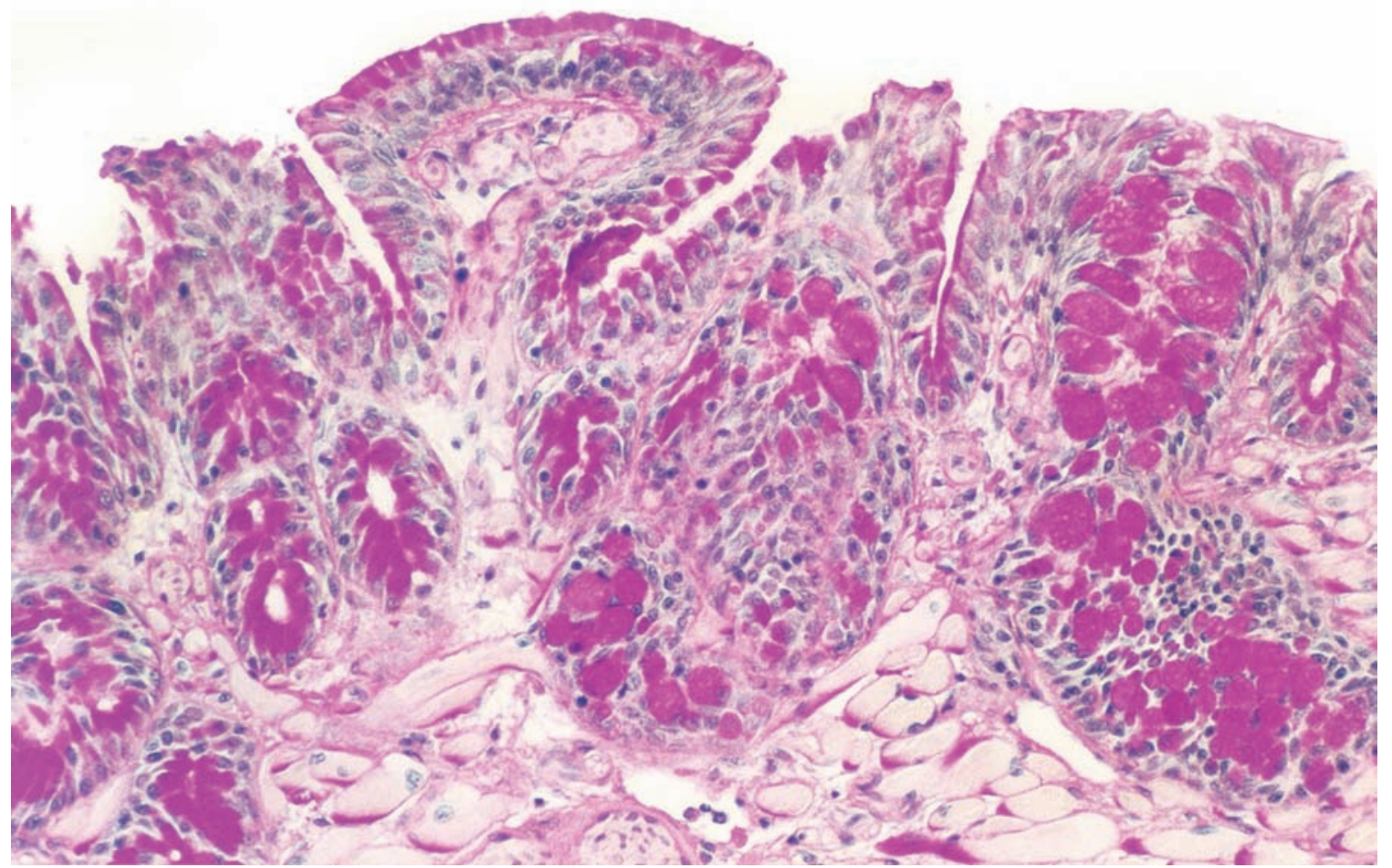

Fig. 1. Aspecto histológico de la superficie dorsal de la lengua de Rana catesbeiana. Observar las células con producto de secreción PAS positivo en las glándulas y en las papilas. PAS-Hematoxilina (140X).

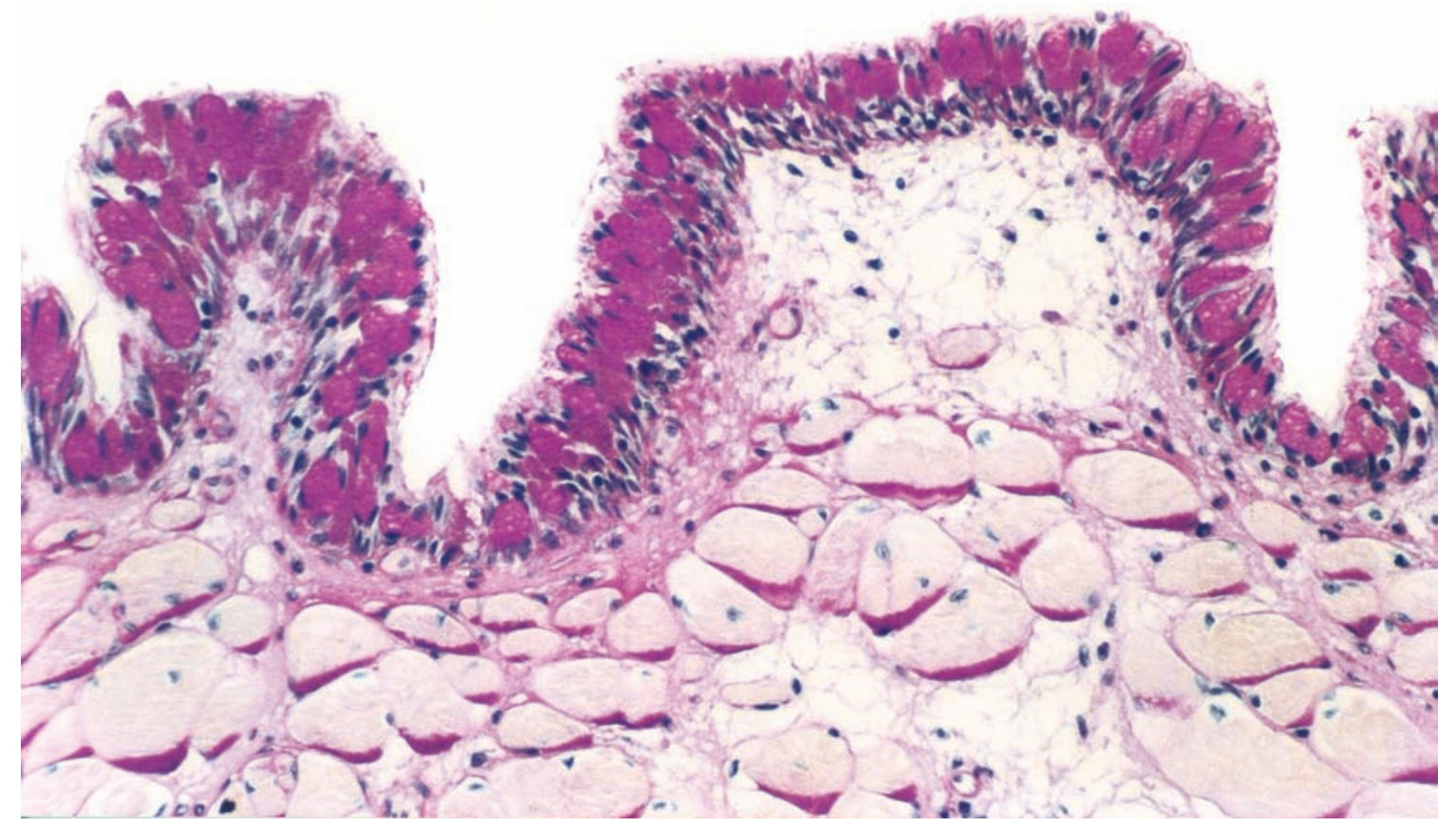

Fig. 2. Aspecto histológico de la superficie ventral de la lengua de Rana catesbeiana. Observar las células mucosas, productoras de secreción PAS positiva. PAS-Hematoxilina (140X). 


\section{DISCUSIÓN}

Los anfibios usan la lengua para la captura de presas. Con esa finalidad, la superficie dorsal posee numerosas células mucosas, cuya secreción sirve como adhesivo. Esa superficie está recubierta por papilas filiformes y fungiformes. Las últimas, ricamente inervadas, actúan como órgano del gusto y, tal vez, del tacto (Rapuzzi \& Casella, 1965). Además de papilas, en la lengua de los anfibios existen abundantes glándulas. En Rana catesbeiana, como en muchas otras especies, las glándulas linguales son de tipo tubular simple, constituidas por células secretoras cilíndricas y células de sostén. Mientras tanto, en Hyla arborea, Rana esculenta y Bufo vulgaris las glándulas son de tipo tubular ramificado (AlbaneseCarmignani et al. 1975) y en Bufo viridis y Rana graeca son tubuloalveolares (Albanese-Carmignani \& Zaccone, 1977). En Triturus marmoratus, Fährmann (1974) describió un tipo de glándula tubular muy ramificado e imbricado.

El producto de secreción de las glándulas linguales de $R$. catesbeiana está compuesto por mucopolisacáridos neutros y proteínas, sin mucopolisacáridos ácidos. De esta manera esas glándulas pueden ser clasificadas como seromucosas, como en la mayoría de los anfibios (Gabe \& St Giron). Sin embargo, en Rana tigrina, Bufo melanosticus, $B$. marinus y Alytes obstetricans las glándulas linguales son serosas (Nalavade \& Varute, 1971; Zylberberg, 1976; Cannata, 1981; González-Elorriaga, 2002), en Bufo melanosticus, B. ictericus, Bombina variegata e Hynobius tokoensis son mucosas (Nalavade \& Varute, 1971; Silva, 1990; Kurabuchi et al., 1995), mientras que en Ichtyophis glutinosos, Discoglossus pictus, Bufo vulgaris, Rana esculenta, $R$. ridibunda e Hyla fuscovaria, son mucoserosas (Zylberberg, 1976; Albanese-Carmignani \& Zaccone, 1974; AlbaneseCarmignani et al., 1975; Navas et al.; Lopes et al.).

Los túbulos glandulares de $R$. catesbiana no poseen células ciliadas, como describió Fährman (1975) en Triturus alpestris, ni células mioepiteliales. La excreción de los productos de secreción ocurre, probablemente, gracias a la contracción de las fibras musculares, íntimamente entrelazadas con la porción terminal de los túbulos, como se observa en Hynobius tokoensis (Kurabuchi) y Salamandra salamandra (Opolka \& Clemen, 1998).

El epitelio de la superficie ventral de la lengua de $R$. catesbeiana está formado por células caliciformes y ciliadas. Según Nalavade \& Varute (1971), la histoquímica permite diferenciar dos tipos de células caliciformes, G1 (con mucopolisacáridos neutros) y G2 (con mucopolisacáridos neutros y ácidos). Así las células caliciformes de $R$. catesbeiana son de tipo G1. En Rana tigrina y Discoglossus pictus las células caliciformes de la superficie ventral de la lengua son de tipo G1 y G2 (Nalavade \& Varute, 1971; Albanese-Carmignani \& Zaccone, 1974).

La superficie dorsal de la lengua de $R$. catesbeiana posee numerosas papilas filiformes y fungiformes. Las papilas filiformes están constituidas por un epitelio simple cilíndrico, con células secretoras que sintetizan mucinas neutras. Las papilas fungiformes están constituidas básicamente por un disco sensorial tapizado por epitelio estratificado cilíndrico, con cuatro tipos de células: basales, periféricas, de sostén y receptoras.

La ultraestructura muestra que el disco sensorial en Rana temporaria, R. esculenta y R. pipiens está recubierto de microvellosidades (Graziadei \& Dehan; Düring \& Andres), mientras que en $R$. catesbeiana, R. nigromaculata, Hyla arborea y Bufo japonicus presenta crestas citoplasmáticas entremezcladas con células con microvellosidades (Graziadei \& Dehan; Jaeger \& Hillman, 1976; Iwasaki et al., 1986; Iwasaki \& Kobayashi, 1988).

Las células mucosas del epitelio lingual de $R$. catesbeiana secretan un moco rico en mucopolisacáridos neutros. La presencia de estas células en el epitelio lingual de $R$. catesbeiana (Iwasaki \& Kobayashi, 1989), es menor que en Bufo japonicus (Iwasaki et al., 1989). En otras especies, como Rana esculenta, R. temporaria, Bufo bufo, Discoglossus pictus, Hyla arborea y Alytes obstetricans, la secreción es rica en mucopolisacáridos débilmente ácidos, asociados a proteínas (Zylberberg, 1976, 1977).

Las células de sostén se disponen formando una hilera ordenada en la superficie apical de la papila fungiforme de $R$. catesbeiana. Secretan un moco constituido por mucopolisacáridos neutros y ácidos (sulfomucinas y sialomucinas). Nalavade \& Varute (1972) llegaron a conclusión similar en Rana tigrina y Bufo melanostictus.

GUIRALDELLI, M.F.; LOPES, R.A.; SALA, M.A. \& LOPES, T.R.V.P. Morphological, morphometrical and histochemical study of the lining and glandular epithelium of the tongue of the bullfrog Rana catesbeiana. Int. J. Morphol., 29(1):226-233, 2011.

SUMMARY: The dorsal surface of the tongue of the bullfrog, Rana catesbeiana, has simple columnar epithelium with a few ciliated cells and goblet cells. The entire surface is covered with numerous filiform papillae and few fungiform. Filiform papillae have a simple columnar epithelium with secretory cells, while the fungiform have a sensory disc on their upper surface the 
lined by a stratified columnar epithelium with basal, peripheral, glandular and receptor cells. Over the dorsal lingual surface there are numerous winding tubular glands, which penetrate deeply into the muscle of the tongue, mingling with the fibers. The gland epithelium is cylindrical with secretory and supporting cells. The first are absolute on the basis of the gland and the latter are rare in the upper third. The ventral surface of the tongue is lined by a stratified epithelium, with the presence of goblet cells, with ciliated cells among them. Morphometrically, lingual glands varies in length, according to their location: shorter in the anterior region of the tongue $(330 \mu \mathrm{m})$ than in the posterior region $(450 \mu \mathrm{m})$. Secretory cells of the anterior lingual glands are smaller $\left(1457.7 \mathrm{~mm}^{3}\right)$ than the posterior ones $\left(2645.9 \mu^{3}\right)$. The same can be said of the cell nuclei, $130.0 \mu \mathrm{m}^{3}$ for the anterior glands and $202.3 \mu \mathrm{m}^{3}$ for the posterior ones. Secretory cells of the lingual glands contain substances rich in protein and neutral mucopolysaccharides, which characterize the seromucous type. Goblet cells of the dorsal and ventral surface epithelia secrete neutral mucopolysaccharides and proteins, and can be characterized as type G1 cells, and the supporting cells of the superficial glands of the fungiform papillae secrete a mucus rich in neutral mucopolysaccharides, sulfomucins and sialomucins.

KEY WORDS: Tongue; Lingual glands; Morphometry; Histochemistry; Rana toro, Rana catesbeiana.

\section{REFERENCIAS BIBLIOGRÁFICAS}

Albanese-Carmignani, M.P.A. \& Zaccone, G. Mucopolysaccharide histochemistry of the lingual glands in Discoglossus pictus Otth (Anuran, Amphibian). Ann. Histochim, Paris, 19: 47-63, 1974.

Albanese-Carmignani, M.P.A. \& Zaccone, G. Histochemical studies on the tongue of anuran amphibians. II. Comparative morphochemical study of the taste buds and the lingual glands in Bufo viridis Laurenti and Rana graeca Boulanger with particular reference to the mocosaccharide histochemistry. Cell Molec.Biol., 22:203-17, 1977.

Albanese-Carmignani, M. P. A.; Zaccone, G. \& Cannata, F. Histochemical studies on the tongue of anuran amphibians. I. Mucopolysaccharide histochemistry of the papillae and the lingual glands in Hyla arborea L., Rana esculenta L. and Bufo vulgaris Laur. Ann. Histochim,, Paris, 20:47-65, 1975.

Cannata, F. Richerche istologiche ed istochimiche sulla lingua de Bombina variegate (Discoglossidae). Riv. Biol. Norm. Patol., 7:131-47, 1981.

Düring, M. V. \& Andres, K. H. The ultrastructure of taste and touch receptors of frog's taste organ. Cell Tissue Res., 165:185-98, 1976.
Fährman, W. Zur Morphologie und Histochemie der Zungendrüse der Marmormolches (Triturus marmoratus Latr.). Z. mikroskAnat. Forsch., 88:238-56, 1974.

Fährman, W. Vergleichende Untersuchungen an den Sekretgrana der Zungendrüse verschiedener Triturus-Arten. Zool. Jb. Anat., 94:346-57, 1975.

Francis, E. T. B. The sources and nature of salivary secretions in Amphibia. Proc. Zool. Soc. London, 136:453-76, 1961.

Gabe, M. \& St. Girons, M. Donnes histologiques sur les glandes salivaires des lépidosauriens. Mem. Mus. Nat.Hist. nat. Paris, 58:1-112, 1969.

González-Elorriaga, M. Las glandulas de la mucosa dorso-distal de la lengua del sapo Bufo marinus L. (Amphibia: Anura): Histologia y ultraestructura. Acta Cient. Venez., 53:49-59, 2002.

Graziadei, P. P. C. \& Dehan, R. S. The ultrastructure of frog's taste organ. Acta Anat., 80:563-603, 1971.

Hammerman, D. L. The frog tongue. II. Histogenesis of fungiform papillae in Rana catesbeiana. Acta Zool., 50:25$33,1969$.

Iwasaki, S. \& Kobayashi, K. Fine structure of the dorsal tongue surface in the Japanese toad, Bufo japonicus (Anura, Bufonidae). Zool. Sci. 5:331-6, 1988.

Iwasaki, S. \& Kobayashi, K. Fine structure of the lingual dorsal epithelium in the bullfrog, Rana catesbeiana. Zool. Sci., 6:259-67, 1989.

Iwasaki, S.; Miyata, K. \& Kobayashi, K. Studies on the fine structure of the lingual dorsal surface in the frog, Rana nigromaculata. Zool. Sci., 3:265-72, 1986.

Iwasaki, S.; Miyata, K. \& Kobayashi, K. Fine structures of the lingual dorsal epithelium of the Japanese toad, Bufo japonicus. Zool. Sci., 6:681-9, 1989.

Jaeger, C. B. \& Hillman, D. E. Morphology of gustatory organs. In: Llinás, R. R.; Precht, W. \& Capranica, R. R. (Ed.), Frog neurobiology: A handbook. Berlin, Springer-Verlag, 1976. pp. 588-606.

Junqueira, L. C. U. \& Araujo, J. H. On three histological peculiarities of the tongue of the toad Bufo ictericus and their probable functional importance (Amphibia - Bufonidae). Rev. Bras. Biol., 58:159-61, 1998.

Kurabuchi, S.; Nakada, H. \& Aiyma, S. Ultrastructural changes of secretory cells of the salamander lingual glands under varying conditions. Anat. Rec., 243:303-11, 1995. 
Lev, R. \& Spicer, S. S. Specific staining of sulphate groups with alcian blue at low pH. J. Histochem. Cytochem., 12:309, 1964.

Lopes, R. A.; Sala, M. A.; Paula-Lopes, T. R. V.; Costa, J. R. V.; Watanabe, I. \& Semprini, M. As glândulas linguais de Hyla fuscovaria. Estudo histológico e histoquímico. Rev. Fac. Farm. Odont. Alfenas, 19:33-5, 1997.

Mazia, D.; Brewer, P. A. \& Alfert, M. The cytochemical staining and measurement of protein with mercuric bromophenol blue. Biol. Bull., 104:57-67, 1953.

McManus, J. F.A. The histological demonstration of mucus after periodic acid. Nature, 158:202, 1946.

McManus, J. F. A. \& Cason, J. E. Carbohydrate histochemistry studied by acetylation techniques. I. Periodic acid methods. J. Exper. Med., 91:651-4, 1950.

Mowry, R. W. Alcian blue techniques for histochemical study of acidic carbohydrates. J. Histochem. Cytochem., 4:407-8, 1956.

Nalavade, M. N. \& Varute, A. T. Histochemical studies on the mucins of the vertebrate tongue. I. Histochemical analysis of mucosubstances in the amphibian tongue. Histochemie, 27:351-65, 1971.

Nalavade, M. N. \& Varute, A.T. Histochemical studies on the mucins of the vertebrate tongue. II. Mucopolysaccharides in cells of taste-buds of tadpoles of Rana tigrina and Bufo melanosticus. Acta Histochem., 43:202-10, 1972.

Navas, P.; Hidalgo, J.; Aijon, J. \& Lopez-Campos, J. L Histochemical study on the tongue of Rana ridibunda (anuran amphibian). Folia Histochem. Cytochem. (Krakow) 19:39-45, 1981.

Opolka, A. \& Clemen, G. The lingual epithelium of Salamandra salamandra: metamorphotic changes during its ontogenesis. Ann. Anat., 180:537-45, 1998.

Opolka, A.; Effing, U.; Wistuba, J. \& Clemen, G. The epithelia of the protrusible tongue of Eurycea longicauda guttolineata (Hoolbrook 1838) (Urodela: Plethodontidae). Eur. J. Morphol., 41:9-22, 2003.

Quintarelli, G. Masking action of basic proteins on sialic acid carboxyls in epithelial mucins. Experientia, 19: 230-1, 1963.

Quintarelli, G.; Tsuiki, S.; Hashimoto, Y. \& Pigman, W. Studies of sialic acid containing mucin in bovine submaxillar and rat sublingual glands. J. Histochem. Cytochem., 9:176-83, 1961.

Rapuzzi, G. \& Casella, C. Innervation of the fungiform papillae in the frog tongue. J. Neurophysiol., 28:154-65, 1965.
Sala, M. A.; Komesu, M. C.; Lopes, R. A. \& Maia Campos, G. Karyometric study of basal cell carcinoma. Braz. Dental J., 5:11-14, 1994

Silva, F. M. Aspectos citoquímicos dos mucócitos de glândulas linguais de Bufo ictericus, Spix 1824 (Amphibia, Anura). Rev. Bras. Ciênc. Morfol., 7:29-32, 1990.

Spicer, S. S. \& Lillie, R. D. Saponification as a means of selectively revearsing the methylation blockade of tissue basophilia. J. Histochem. Cytochem., 7:123-5, 1959.

Spicer, S. S.; Horn, R. G. \& Leppi, T. J. Histochemistry of connective tissue mucopolyssacharides. In: Wagner, B. M. \& Smith, D. E. (Eds.): The connective tissue. International Academy of Pathology Monograph 7. Baltimore Williams \& Wilkins, 1967. pp. 251-303.

Stensaas, L. J. The fine structure of fungiform papillae and epithelium of the tongue of a South America toad, Calytocephalella gayi, Am. J. Anat., 131:443-62, 1971.

Tucker, R. Taxonomy of the salivary glands of vertebrates. Syst. Zool., 7:74-83, 1958.

Vialli, M. Tecnica pel l'uso contemporaneo in istochimica dell'alcian bleu e della reazione di Hotchkins. Arch.Zool.Ital., 40:399-407, 1955.

Wiedersheim, R. Die Anatomie der Gymnophionen. Jena, Gustav Fisher-Verlag, 1879. pp. 101.

Wistuba, J.; Opolka, A. \& Clemen, G. The epithelium of the tongue of Ambystoma mexicanum. Ultrastructural and histochemical aspects. Ann. Anat., 181:523-36, 1999.

Yu, W.; Nakamura, A.; Nakahari, T. Imai, Y. \& Senda, T. Classification of the frog lingual gland cells and their exocytotic features. J. Electron Microsc., Tokyo, 47:73-80, 1998.

Zylberberg, L. Donées histologiques sur les glandes linguales de quelques batraciens anoures. J. Biol. Buccale, 4:237-59, 1976.

Zylberberg, L. Histochemistry and ultrastructure of amphibian lingual glands and phylogenetic relations. Histochem. J., 9:505-20, 1977.

Dirección para correspondencia:

Prof. Dr. Ruberval Armando Lopes

Faculdade de Odontologia de Ribeirão Preto

Universidade de São Paulo

Avenida do Café s/n

CEP 14040-904

Ribeirão Preto - SP

Recibido : 19-09-2010

BRASIL

Aceptado: 26-11-2010

Email: ruberlopes@yahoo.com.br 